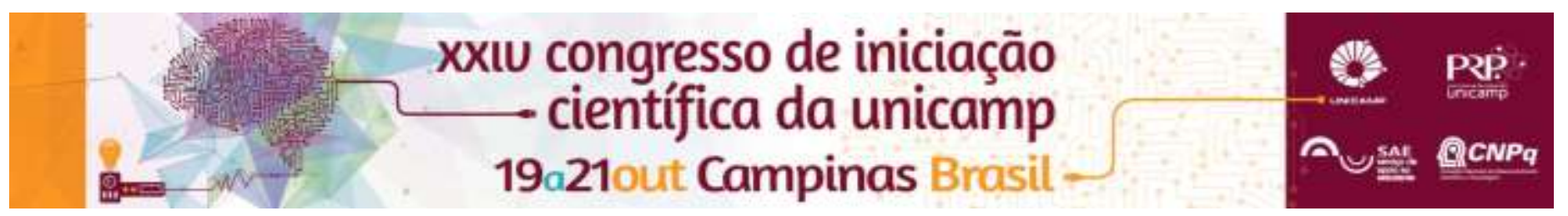

\title{
Online SPE-CE-UV for the determination of folic acid: investigation of different sorbents
}

\author{
Regiane H. Oliveira*, Zuzana Cieslarová, Fernanda M. Oliveira, César R. T. Tarley, Ana V. C. Simionato.
}

\begin{abstract}
The aim of this work was to compare commercial (C18, SAX and HLB) and molecularly imprinted polymer SPE sorbents for extraction and preconcentration of folic acid by SPE coupled online to CE-UV. This method will be applied for analysis of folic acid in wheat flours in the future.
\end{abstract}

Key words: Folic acid, preconcentration, online SPE-CE.

\section{Introduction}

Folic acid is a B vitamin that prevents malformations that occur in the early stages of fetal development. When there is the closure of the neural tube of the fetus, the baby may have deformations such as anencephaly, paralysis of the lower limbs and mental retardation in some cases. In Brazil, flour fortification with iron and folic acid is required in order to reduce the incidence of anemia and diseases of the neural tube. ${ }^{[1]}$

Capillary electrophoresis (CE) is a high-efficient analytical separation technique that uses low volumes of solvents and samples, but may exhibit low detectability. [2] The use of solid phase extraction coupled to CE online (SPE-CE) allows the extraction, preconcentration and analysis of the sample simultaneously. In this work we have compared commercial sorbents such as SAX, C18 and HLB, with molecularly imprinted polymers (MIPs), based on poly(methacrylic acid-trimethylolpropane trimethacrylate) $/ \mathrm{SiO}_{2}$, which are obtained by polymerization in the presence of a template molecule to be imprinted, resulting in highly specific sorbent for extraction of folic acid. The MIP evaluated in this work has already been used for determination of folic acid in

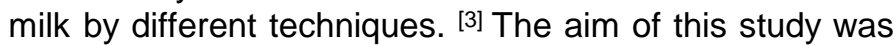
to develop a method of separation and pre-concentration of folic acid by SPE-CE-UV for future analysis of flour and food supplements.

\section{Results and Discussion}

The concentration and $\mathrm{pH}$ of borate solution used as background electrolyte (BGE) were optimized. The addition of ascorbic acid and hydrazine as a stabilizer for the folic acid solution was also evaluated. The optimized conditions were: BGE composed by $100 \mathrm{mmol} \mathrm{L}^{-1}$ borate ( $\mathrm{pH}$ 9.5); voltage: $20 \mathrm{kV}$; injection time: $15 \mathrm{~min}$ (50 mbar). The separation was performed in a fused silica capillary with an effective length of $70 \mathrm{~cm}$ and internal diameter of $50 \mu \mathrm{m}$. Image 1 shows the scheme of the SPE cartridge coupled to the CE capillary.

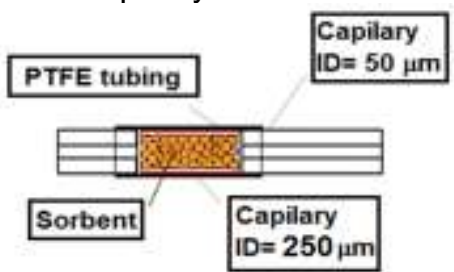

Figure 1. Coupling scheme for fabrication of online SPE. ${ }^{4}$
Table 1. Figures of merit for CE-UV method.

\begin{tabular}{|c|c|}
\hline Linear range $\left(\mu \mathrm{mol} \mathrm{L}^{-1}\right)$ & $9.97-140$ \\
\hline Sensibility $\left(\mathrm{mAU} \mathrm{L} \mathrm{mol}^{-1}\right)$ & 28970 \\
\hline Linear regression $\left(\mathrm{R}^{2}\right)$ & 0.9991 \\
\hline $\mathrm{LQ}(\mu \mathrm{mol} \mathrm{L}$ & -1 \\
\hline $\mathrm{LD}\left(\mu \mathrm{mol} \mathrm{L}^{-1}\right)$ & 9.97 \\
\hline Intra-day precision & 2.99 \\
\hline Accuracy & $6 \%$ \\
\hline
\end{tabular}

Sorbents like C18, SAX and HLB were compared by offline SPE for later use in online SPE-CE. SAX and HBL showed the best recoveries of folic acid. MIP sorbent for online SPE-CE is still under evaluation.

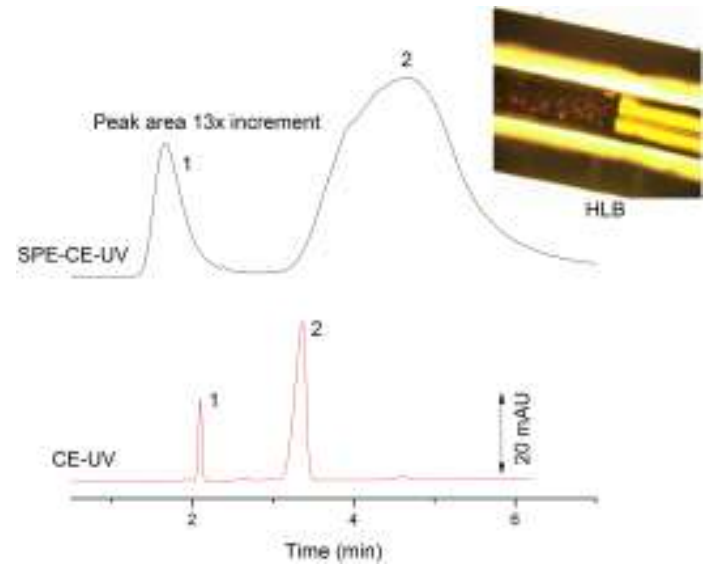

Figure 2. Comparison of separation of theophylline (1) and folic acid (2) by CE-UV (red) and SPE-CE-UV online using HLB sorbent. Conditions: BGE: ammonium acetate $5 \mathrm{mmol} \mathrm{L}^{-1} ; 1 \mathrm{~min}$. sample loading, eluent: $A C N$ :Borate $100 \mathrm{mmol} \mathrm{L}^{-1}(1: 1, \mathrm{v} / \mathrm{v})$.

\section{Conclusions}

The CE method for analysis of folic acid was developed and validated, presenting excellent figures of merit. Various sorbents were compared by offline SPE for later use in online SPE-CE. The offline extraction with polymeric sorbent Oasis ${ }^{\circledR}$ HLB showed better recovery of folic acid. The online SPE-CE investigation with HLB and MIP sorbent is still in progress.

\section{Acknowledgement}

FAPESP, CAPES and CNPq.

\footnotetext{
${ }^{1}$ Resolução RDC n ${ }^{\circ}$ 344, de 13 de dezembro de 2002.

2 Vaza, F. A. S.; Oliveira, C. L. M.; Oliveira, M. A. L.; "Fundamentos de eletroforese capilar: uma abordagem por animações"; Química Nova, Vol. 38 , No. 5, 732-737, 2015.

3 Oliveira, F. M.; Segatelli, M. G.;Tarley, C. R. T.; Anal. Methods, 2016, 8 , 656

${ }^{4}$ Maijó, I.; Borrul, F.; Callull, M.; Aguilar, C. Electrophoresis 2011, 32, 2114. XXIV Congresso de Iniciação Científica da UNICAMP
} 